\title{
Paideusis
}

\section{Teaching Women: Feminism and English Studies (Ann Thompson and Helen Wilcox (Eds.))}

\section{Kathleen Thomson}

Volume 7, Number 1, 1993

URI: https://id.erudit.org/iderudit/1073287ar

DOI: https://doi.org/10.7202/1073287ar

See table of contents

Publisher(s)

Canadian Philosophy of Education Society

ISSN

0838-4517 (print)

1916-0348 (digital)

Explore this journal

Cite this review

Thomson, K. (1993). Review of [Teaching Women: Feminism and English Studies (Ann Thompson and Helen Wilcox (Eds.))]. Paideusis, 7(1), 43-46. https://doi.org/10.7202/1073287ar viewed online.

https://apropos.erudit.org/en/users/policy-on-use/ 


\section{Book Review}

Ann Thompson and Helen Wilcox (eds.). Teaching Women: Feminism and English Studies. Manchester: Manchester University Press, 1989

The April 1991 edition of Harper's magazine contains a provocative article entitled "Debate the Canon in Class" in which the author, Gerald Graff, describes a dispute he witnessed in the faculty lounge of Northwestern University, a dispute he claims typifies the larger ideological controversy currently infiltrating North American campuses. In this documented confrontation between two English department colleagues, an older male professor laments that one of the great masterpieces of the Western cultural heritage, Amold's "Dover Beach," seemingly holds no appeal for modern college students, and that he, who is moved by the language and image within the poem, cannot convey a sense of this beauty to the apathetic students he teaches. A young female professor, showing no sympathy for her older colleague's pedagogical plight, retorts that "Dover Beach," with what she claims is its relegation of the unnamed female in the poem to a position outside politics and history, should either be deleted from the compulsory curriculum or, better yet, taught in light of what the poem really is - a celebrated form of phallocentric discourse representative of the entire bulk of Western canonical works.

Graff's central argument is that the conflict exemplified by the two perspectives above-the view that "Dover Beach" has nothing to do with gender politics, and the feminist standpoint that it has everything to do with it $\rightarrow$ should not be confined to academic backrooms but, rather, brought forth in classrooms for students to consider and debate themselves. Graff claims that broadening current curricula with an inclusion of populist or alternative works will not guarantee students' participation in literary culture unless this emphasis on revised content is accompanied by teachers' willingness to make controversy itself an object of study in the classroom. In other words, encouraging open challenges to the conception of classic literature as a great repository of transcendent values immune to the flux of time or cultural context might help engage those students currently disenchanted with traditional views of literary culture, and so dissolve the complacency characterizing too many English classrooms. In his words, "there are worse things that could happen to literature than having a passionate controversy erupt over it." There is no doubt, then, that Graff would welcome publication of the volume under discussion here as one fruitful step toward making that controversy open to scrutiny and discussion.

Teaching Women: Feminism and English Studies is an edited collection of sixteen essays dedicated to exploring feminist teaching practice in postsecondary settings. The book is eclectic in the sense that the teaching contexts and course material under consideration by the authors vary widely in focus. For example, the articles tackle such diverse issues as how a women's writing course might be organized around autobiographical study; why traditional course syllabi might be enriched through fostering gender conscious reading perspectives; and the ways in which "patriarchal" learning methodologies might be overthrown by incorporating in the classroom those collaborative learning strategies said to be specifically "feminine." Yet, what links this 
somewhat disparate collection thematically is the authors' shared belief in a distinct feminist pedagogy that can counter hierarchical curricula, practices, and assessment procedures that seemingly disempower female students of literature. Teaching Women, say its editors, serves as a manual that both celebrates the existence of such a liberatory pedagogy and offers insightful teaching guidelines for those dissatisfied with mainstream academic practice. The remainder of this review will be concerned with whether or not the book satisfies its professed revisionary goals.

For organizational purposes, Teaching Women is divided into five sections, each of which addresses a specific educational concern such as increasing women's access to higher education, valuing women's supposedly alternative modes of reading and writing, and formulating courses that either reaffirm the value of marginal texts or reinterpret established works from a feminist perspective. In reality, however, there is much overlap in terms of the topics the contributors choose to address. In my estimation, the book deals with only two central themes: the need for classroom objectives and methodologies to reflect women's experiential ways of knowing, and the need to "feminize" the subject of English by refusing to endow traditional literary texts with any particular status, choosing instead to view the majority of them as the product of a phallocentric culture that has systematically erased women's tradition.

The first of these themes is explored in the two initial sections of the book and the resulting prescriptions for feminist teaching are, in my opinion, less than satisfactory. Despite the assertion in the text's Afterword that a belief in a distinct "women's culture/writing" does not entail essential ist presuppositions regarding a uniform female experience, the various contributors to these two sections seemingly accept the idea that women as a collective learn best when small group, collaborative endeavour comprises the majority of classroom activity, and when women's affective responses to literature are given precedence over other forms of literary analysis. For instance, Susan Sellers claims in her article that, by utilizing various poststructuralist techniques proposed by Helene Cixous, the teacher of literature can establish distinctly feminist reading and writing modes which avoid literary theories that only distance the reader from the text, and focus on alternative forms of expression (journals, creative writing, drama) to the standard literary essay. In a similar vein, Maggie Humm advocates that women both study and write autobiography because, according to her, life history writing validates women's subjective voices, voices that diametrically oppose the linear, rational thought identified with males. Likewise, Moira Monteith defends classrooms that depart from formal modes of literary discourse and emphasize instead the personal and co-operative response to female texts that are themselves autobiographical in nature.

While I do not doubt that these recommended methodologies have a certain place in the English classroom, the underlying thesis that most or all women possess a natural affinity towards collaborative, experiential exploration of literature, an affinity existing in opposition to modes of study preferred by males, is highly problematic. First of all, the authors concerned define the intellectual requirements of women as different from those of men, yet, this difference is itself characterized as excessively uniform. Yet in actuality, it is doubtful that female learning modes are as homogeneous as the contributors to this edition seem to imply; certainly the idea of a universal female experience 
that somehow transcends cultural or class contingencies requires justification that the authors are unable or unwilling to provide. In addition, the criterion that supposedly distinguishes feminist from masculinist scholarship-that is, women's general attention to emotive, egalitarian response can in one very important sense be said merely to replicate in acritical fashion the standard Western conception of women as intuitive, nonrational knowers. Because the authors fail to question the essentialist assumptions that guide their recommendations for feminist practice, the preliminary two sections of Teaching Women disappoint rather than enlighten. Indeed, the reader may remain unconvinced that the approaches advocated are in any conclusive sense "feminist," for it would seem that many of the proposed study techniques are merely practical options that might be utilized in any coeducational English classroom.

The remaining, more comprehensive sections of the book-those that in general question the validity of the accepted literary canon - have in my mind far more appeal than the preliminary chapters. While the authors of these essays unanimously agree that good literature can never transcend the circumstances of its creation and reception, and so cannot embody aesthetic values that are universal, the most thoughtful among them avoid extremist positions such as calling for a complete censorship of all male authors who, by virtue of their very gender, are often considered capable of producing only misogynous texts. Instead, their articles query, at least to an extent, those tiresome and indefensible assumptions that all literary works by men are by definition "masculinist," or that the criterion of an author's gender is the sole means by which a text's worth is to be judged. Ann Hancock's and Elspeth Graham's two articles, for example, examine, in part, the tension between wishing to introduce conventionally valued texts to young readers, and desiring on the other hand to infuse one's teaching with a new feminist awareness. Graham, in particular, tacitly recognizes the potential danger that an inclusive attention to feminist literary analysis might merely endorse yet another form of classroom orthodoxy.

None of the essays, however, suggests a workable means by which to resolve such ambivalences, and the weakest among them opt for solutions that are methodologically and conceptually suspect. Su Reid, for example, in her "Learning to Tread as a Woman," operates from the assumption that she and fellow female readers have traditionally learned to interpret texts as "honorary men." To resolve this problem and thereby reconstruct themselves as female readers, Reid, borrowing a technique originated by Dale Spender, recommends that students rewrite passages from classic texts by substituting female for male pronouns. She likewise advocates what she terms "reinventing" female characters, which essentially entails exposing the misrepresentation of women's lives in such male-authored narratives as Dickens' Our Mutual Friend and Wordsworth's The Solitary Reaper. According to Reid, this sort of analysis makes explicit the hidden malevolence towards women's pain that infuses the works of classic male writers. Despite the fact that Reid states her students could not identify with any consistency the writer's sex when selected literary passages were deliberately presented anonymously, she nonetheless refuses to question the dubious value of equating simplistic exercises in pronoun substitution with the complexity required of truly gender conscious textual readings. 
I have deliberately singled out Reid's essay for discussion as I think it illustrates why Teaching Women ultimately fails to fulfil its professed intention to define an emancipatory pedagogy that overcomes the limitations of patriarchal classroom practice. My principal objection to the latter part of this volume is that too many of its contributors seem to suppose that women as readers do not just identify with, but actually come to "inhabit" emotionally the thoughts and actions of fictional male protagonists. In other words, the sense of a female self is supposedly annihilated by a forced and continual adoption of strictly male modes of thinking and reacting to the world. I am not convinced, however, that this is the manner in which females actually or always read male texts; I think rather that the reader, whether male of female, generally assumes some distance from the text and, despite the intense psychological identification that can occur between reader and character, never fully abdicates the status of observer.

As a second objection, I believe the various authors successively evade those issues that present obvious challenges to many of their shared premises. For instance, it is undeniable that many men have written extremely sensitively and well about the female condition. As Reid's exercise on anonymous literary passages inadvertently reveals, these authors cannot be readily accused of marginalizing or misrepresenting women's concerns. In addition, regarding gender as the prime analytic determinant of literary interpretation seems to reinforce the notion that sexual orientation completely dictates males' creative abilities, yet simultaneously liberates female writers and readers from the prisonhouse of gender bias. In my mind, this is reductionism at its worst. While the authors under review here are not uniformly guilty of such reductive presuppositions, many of the essays overtly or covertly reinforce the belief that women's minds have been systematically colonized by male authors whose sole purpose has been to assimilate female into male experience. Yet, a loving, attentive study of literature surely requires more than the blanket categorization of texts into two warring subsets-those written by males who render female sensibility invisible, and those written by females who make visible all that their sex has previously relinquished and/or lost. Surely, if it were this simple, any debate over desirable English content would evaporate, for what would distinguish good from bad literature would be a consideration of the author's particular sex. Those of us familiar with certain women-authored best sellers flooding the popular literary market might not be comfortable with such a facile appeal to gender as the sole determining variable.

In the "Afterword," Penny Florence tells us that, with reference to her feminist standpoint, she has been repeatedly accused of a "certain wildness;" of providing "some interesting insights, but flawed judgments." This statement regarding her capacity to theorize captures, however unintentionally, the overall substance and quality of this book. Teaching Women can be said to offer at best an equivocal contribution to the task of justifying a distinct feminist teaching practice, a practice that promises genuinely liberating options for both female and male readers. Despite the publication and subsequent circulation of this book, the jury is still out in terms of any concrete resolution to the controversy agitating the world of letters. In the contentious literary ring, "Dover Beach" has not yet received any final, knockout blow.

Reviewed by Kathleen Thomson, Simon Fraser University 